\title{
O relato pessoal e as estratégias discursivas nas ondas do rádio
}

\section{Personal experiences and discursive strategies in radio}

Patrícia Rodrigues Tanuri Baptista*

Faculdade Novos Horizontes

RESUMO: A presente investigação focaliza conversaçōes telefônicas entre ouvintes e locutores de rádio e tem como objetivo principal investigar, em dois diferentes programas, as estratégias discursivas que os interactantes usam no processo de coconstrução de relatos pessoais. Trata-se de um trabalho de microanálise do discurso, na área da Sociolinguística Interacional (GUMPERZ, 1982; TANNEN, 1984, 1989; SCHIFFRIN, 1996). A análise revela que, em cada programa, o relato pessoal, além de funcionar na busca de construção de relações de proximidade, reflete também a coconstrução de identidades sociais e de papéis preestabelecidos para cada um dos programas.

PALAVRAS-CHAVE: identidade; linguagem; estratégias discursivas; rádio.

ABSTRACT: This research focuses on telephone conversations between addressees and radio announcers. The main aim of this work is at describing, analysing and comparing, in two different radio programmes, the discursive strategies interactants adopt during the process of co-construction of their personal experiences by means of narratives. This investigation is framed by Interactional Sociolinguistics discursive micro-analysis (GUMPERZ, 1982; TANNEN, 1984, 1989; SCHIFFRIN, 1996). The results show that in each programme the personal account or narrative, besides functioning in search of closeness between interactants, also portrays the co-construction of social identities and the established functions of each of the programmes.

KEYWORDS: identity; language; discursive strategies; radio.

* patricia.baptista@unihorizontes.br 


\section{Introdução}

Neste trabalho, ${ }^{1}$ estamos definindo o relato pessoal conforme Linde (1993), como um "importante recurso social na criação e manutenção da identidade, na medida em que contamos aos outros os eventos que nos tornaram o que somos, transmitindo-lhes o que devem saber sobre nós para nos conhecerem" (LINDE, 1993, p.20, apud BASTOS, 1999). Ressalta-se, entretanto, que, em nossos dados, não estamos adotando a definição de narrativa de Labov e Waletzky (1967) e Labov (1972) que pressupōem quatro características: remeter a um acontecimento em especial, ser estruturada em sequência temporal, ter um ponto e ser contável. Neste trabalho, o relato pessoal se define como uma descrição de uma ação habitual que constrói e demarca o self e não necessariamente se organiza em uma sequência cronológica. Veremos que, através do relato ou descrição do self, o participante, ao mesmo tempo, expressa e reafirma a sua identidade calcada na sua realidade social, construindo o que Schiffrin (1996) considera como um autorretrato.

Assim, o relato pessoal constitui-se em um recurso utilizado, especialmente, pelos ouvintes-participantes das interaçóes e se concretiza nos dois programas em análise: "Rádio Vivo" e "Capital na boca do povo". Em cada um deles, o uso dessa estratégia, além de funcionar na busca de construção do enquadre pessoal e de identidades sociais, reflete os papéis institucionais preestabelecidos para cada um dos programas. Assim, na estrutura de participação do programa "Rádio Vivo", o relato surge em função da atividade prevista para o papel de ouvinte: participar do debate do dia. Já no "Capital na boca do povo", essa estratégia está relacionada à atividade fazer pedidos por ajuda, funcionando como uma justificativa.

Ressalta-se, assim, a realização de uma análise empírica, de natureza essencialmente qualitativa, interpretativa, considerando a fala contextualizada. Trata-se, portanto, de análise local, situada, na medida em que estudamos a interação em situações reais, observando suas particularidades, em relação tanto com o contexto imediato de ocorrência quanto com estruturas sociais mais amplas.

Para esta reflexão, foram selecionados dois programas de rádio pertencentes a diferentes estaçôes nos quais se evidencia uma participação

\footnotetext{
${ }^{1}$ Este artigo é resultante da minha pesquisa de doutorado intitulada "Nas ondas do rádio: um estudo da coconstrução do enquadre pessoal", orientada pela Professora Doutora Vera Lúcia Menezes de Oliveira e Paiva.
} 
maciça de ouvintes: "Rádio Vivo" (Itatiaia AM) e o "Capital na boca do Povo" (Capital AM). A escolha desse corpus justifica-se não só por se tratar de programas, cuja participação de ouvintes ao telefone é efetiva e recorrente, mas também e, principalmente, por serem programas que promovem interaçôes, no geral, longas que acabam por levar à coconstrução do enquadre pessoal. $\mathrm{Ou}$ seja, mesmo contendo outros tipos de seçôes (como jornalismo, publicidade, informações meteorológicas e entrevistas), os programas selecionados dão ao ouvinte a oportunidade de vários turnos de fala e não somente dois ou três, como acontece comumente em rádios FM (Frequência Modulada) em que o ouvinte liga para votar em uma música preferida ou participar de uma brincadeira. As rádios AM (Amplitude Modulada) se mostraram, portanto, como mais profícuas para a análise do fenômeno em estudo: a coconstrução do enquadre pessoal em interações ouvinte-locutor de rádio.

Destaca-se, inclusive, que, com o objetivo de coletar dados reais do comportamento linguístico, os participantes das interações não sabiam que os seus textos conversacionais seriam objeto de análise. Assim, os dados foram gravados em fita magnética de áudio e, posteriormente, transcritos, sem redução ou edição dos textos orais analisados, segundo normas anexas, contabilizando trezentas páginas de transcrição.

A seguir, apresentamos um exemplo de interação em cada programa seguido de sua análise.

\section{O Programa “Rádio Vivo” (Rádio Itatiaia AM)}

De um modo geral, as interações ouvinte-locutor no programa "Rádio Vivo" apresentam uma estrutura que se desenvolve, basicamente, a partir do que Sacks, Schegloff e Jefferson (1974) chamam de par adjacente perguntaresposta. Em outras palavras, a participação do ouvinte é sempre motivada por uma pergunta diária que é colocada no ar, logo na abertura do programa. Tais perguntas (diferentes a cada dia) tratam de tópicos que refletem, quase sempre, um alto grau de seriedade - retratando problemas do cotidiano de pessoas carentes - e buscam o engajamento do ouvinte em uma questão pessoal. Em função disso, observamos um padrão recorrente de participação: geralmente, os ouvintes que ligam o fazem para participar do debate, dando exemplos da questão em discussão e, frequentemente, falam da própria vida, de assuntos essencialmente particulares, revelando suas percepçóes, seus pensamentos e sentimentos, como se estivessem conversando com um amigo. 
Essa estrutura adjacente pergunta-resposta revela um footing ${ }^{2}$ muito semelhante ao da entrevista jornalística, na medida em que locutor e ouvinte se mantêm, respectivamente, nas ações de fazer perguntas e dar respostas, como também observaram, em seus dados, Heritage (1984) e Greatbatch (1988). A adoção desse footing também se evidencia em propriedades linguísticodiscursivas presentes na participação de ambos os interlocutores.

Podemos perceber que, desempenhando o papel de entrevistador, o locutor é aquele que inicia a conversa, apresenta o assunto, propõe perguntas ao ouvinte, controla o tópico e encerra a interação, mantendo uma postura de neutralidade estratégica que o torna capaz de alinhar-se com diferentes opinióes e, portanto, com diferentes ouvintes, construindo uma relação de proximidade não só com os ouvintes com quem interage mas também com a audiência idealizada do programa, já que não explicita sua própria opinião, concordando ou discordando dos ouvintes. Além disso, a ocorrência frequente de backchannels ${ }^{3}$ evidencia um estilo interacional, conforme Tannen (1989), de 'alta consideração', demonstrando não só interesse, envolvimento mas também respeito por aquilo que o ouvinte tem a dizer, seja sua opinião sobre o assunto, seja sua história pessoal, o que resulta no realce da construção de uma relação entre os interlocutores que, segundo Bazzanela (1990), se explicita na demonstração de atenção, compreensão e empatia.

O locutor demonstra, portanto, (como um atributo social reivindicado para a construção de sua identidade nesse programa) ser capaz de manter-se, estrategicamente, neutro e imparcial nas interações com os ouvintes, evitando o impacto que uma discordância poderia acarretar e, mantendo, assim, um clima interacional amigável. É importante que se ressalte, contudo, que essa neutralidade é uma estratégia usada pelo locutor para poder se alinhar com opiniōes antagônicas e, portanto, com diferentes ouvintes, mantendo um footing próprio da entrevista jornalística em que ele assume o papel de

${ }^{2}$ Goffman (1998) introduziu o termo footing para descrever como os participantes enquadram os eventos e, ao mesmo tempo, negociam as relações interpessoais, ou "alinhamentos", que constituem tais eventos. Para o autor, a mudança de footing evidencia uma mudança de postura, de posicionamento, de projeção pessoal do(s) participante(s).

${ }^{3}$ Os backchannels são as pistas de retorno de canal, como: "hum" (linhas 9, 18) e "sei" (linha 12). Segundo Bazzanela (1990), devem ser considerados marcadores interacionais, na medida em que o seu uso implica um realce das relaçôes sociais entre os interlocutores. 
entrevistador, evitando, assim, um possível embaraço na interação que um choque de opinióes com o ouvinte poderia causar.

Para a manutenção dessa postura imparcial, vimos que o locutor se utiliza das seguintes estratégias: 'intensificar interesse do ouvinte', 'procurar acordo' e 'evitar desacordo', que se concretizam, respectivamente, por meio dos recursos: tag questions, ${ }^{4}$ repetição da ideia ou do enunciado do ouvinte e formulação.

O ouvinte, por sua vez, é o interlocutor que, em geral, liga para participar do debate, respondendo à pesquisa do dia, alinhando-se, portanto, como o entrevistado, aquele que responde ao que lhe é perguntado pelo locutor, muitas vezes, engajando-se em uma questão pessoal, utilizando-se do recurso de introduzir relatos pessoais por meio dos quais ele se faz conhecer e busca construir sua identidade, compartilhando não só com o locutor com quem interage mas também com a audiência do programa, seus problemas particulares. As interações ouvinte-locutor no programa "Rádio Vivo" são engendradas, portanto, com base na construção de um ethos que se pauta pela demonstração de empatia, concordância e consideração, em que os interlocutores corroboram a projeção de identidade um do outro, mostrando-se interlocutores cooperativos e coconstruindo uma relação de proximidade entre si e em relação à audiência idealizada, quer seja por meio da estratégia 'procurar acordo' (por parte do locutor), que consiste na mais recorrente nos dados desse programa, quer seja por meio de relatos pessoais (por parte do ouvinte).

Esse sentido de empatia, concordância, consideração e, sobretudo, de cooperação próprio do ethos que os participantes constroem para as interações no "Rádio Vivo" também se explicita na vinheta que é veiculada durante o

${ }^{4}$ Tag questions referem-se aos marcadores de apoio na audiência (terminologia utilizada por MACEDO; SILVA, 1988, apud PEREIRA, 1993), como "né", "sabe", "entendeu". Em nossos dados, tais partículas assumem a função de envolver o outro na troca conversacional, na medida em que solicitam sua participação, quer seja fornecendo uma informação, quer seja dando uma confirmação. No "Rádio Vivo", o uso dessa estratégia assumirá, além da função de envolver o outro, também a função de permitir ao locutor a adoção de uma postura estrategicamente neutra, ou seja, permitir que o locutor se isente de um posicionamento explícito, evitando dar sua opinião em relação ao tópico em discussão. Tal neutralidade estratégica habilita o locutor a se alinhar com opinióes antagônicas e, portanto, com ouvintes diversos, evitando o impacto que uma discordância poderia causar à interação e ampliando, assim, um leque de concordância, de identificação em relação à audiência idealizada. 
programa - "Rádio Vivo: o programa que respeita a sua inteligência” - que, de certa forma, pressupóe e explica a postura de neutralidade assumida pelo locutor. As interaçōes no "Rádio Vivo" definem-se, entretanto, não somente como um ethos de polidez positiva mas também de polidez negativa, ${ }^{5}$ por manter relações de maior formalidade e, sobretudo, de deferência entre os interlocutores, o que se evidencia, especialmente, na frequência da estratégia 'procurar acordo' e no estilo de 'alta consideração' que demonstra preocupação do locutor com as necessidades da face negativa do ouvinte, à medida que são constantes os backchannels e raras as interrupções que, quando acontecem, são sobreposições cooperativas. Vejamos a interação transcrita abaixo, que teve a duração de 4 minutos e 18 segundos:

(1)

José Lino: locutor

Conceição: ouvinte

1. José Lino: eu vou falar com a Conceição

2. bom dia Conceição

3. Conceição: OI, José Lino

4. José Lino: Oi

5. Conceição: eu não aconselho ninguém

6. a tomar remédio pra emagrecer sabe?

7. José Lino: não aconselha

8. Conceição: não porque eu quando eu tinha CEM quilos

9. José Lino: hum

10. Conceição: eu peguei a tomar remédio com receita médica

$11 . \quad$ tudo direitinho

12. José Lino: sei

13. Conceição: aí eu emagreci

14. depois eu parei de tomar o remédio

15. porque o remédio atrapalhou a minha cabeça

16. José Lino: ah É???

17. Conceição: É

18. José Lino: hum

${ }^{5}$ Sobre Polidez Positiva e Negativa, ver Brown e Levinson (1987). 
19. Conceição: o remédio atrapalhou a minha cabeça

20. então eu parei de fazer de tomar o remédio

21. e passei pra cento e cinquenta quilos

22. José Lino: o que que aconteceu com a sua cabeça?

23. você começou a ficar esqueci::da

24. o que que era?

25. Conceição: NA:: da foi eu fiquei DOIda

26. José Lino: ficou DOIda

27. Conceição: fiquei até no (Galba) Veloso

28. amarrada

29. José Lino: é MESmo?

30. Conceição: É

31. José Lino: hum

32. Conceição: então José Lino

33.

34.

eu parei de de de fazer o regime outra vez

aí agora quando foi

35.

aí então engordei cento e dez quilos

36. no fim do ano eu fui internada muito RUim

37. perdendo muito sangue aquela coisa toda

38. deu diabete em mim e fiquei é:

39. a cabeça não atrapalhou mais não

40.

41.

42. José Lino: aí a nutricionista do hospital que eu fiquei internada passou um regime pra mim

43. Conceição: cê acredita qu eu já perdi::

44. e eu tava com cento e dez quilos

45. ontem eu pesei

46.

47. que eu fui no endocrinologista

48. José Lino: hum

49. Conceição: fazer só o regime de boca

50.

51. José Lino: que ele falou no papel pra mim

52. Conceição: já tô com oitenta e dois quilos graças a Deus

53. José Lino: É:: tá abaixando né?

54. Conceição: TÁ abaixando então eu tenho problema de diabete tamBÉM 55. e eu sei que o remédio fez tudo de ruim comigo

56. que eu tava tomando 
57. José Lino: e você tomou com com acompanhamento médico

58. Conceição: ÉÉ::

59. mas depois

60. quando eu fiquei com a cabeça ruim eu parei tudo

61. José Lino: quer dizer que você não aconselha [ninguém?

62. Conceição:

63.

a tomar remédio pra emagrecer

[não aconselho ninguém]

64.

a gente tem que fazer é um regime de boca

65. José Lino:

Oh Conceição ficar com a cabeça ruim

66. deve ser um SOfrimento né?

67. Conceição: ah meu filho eu fiquei doidinha

68. José Lino: [é que horror

69. Conceição: [ eu parei de tomar o remédio ]

70.

e agora eu tô fazendo alimentação

71.

assim não como arroz não como massa nem macarrão

72.

nem nada assim que

73.

conforme a verdura não pode comer também

74.

então eu tô fazendo o regime tudo direitinho

75.

já tô com oitenta e dois quilos de novo

76.

e tô emagrecendo

77. José Lino: tá bom

78. Conceição: viu?

79. José Lino: falou Conceição

80. Conceição: tá bom José Lino

81. José Lino: um abraço viu?

82. Conceição: um bom dia pro cê

83. José Lino: pra você tamBÉM

84.

tchau::

Nessa transcrição, merece destaque o papel importante das repetições de ambos os interlocutores no curso da interação. Logo na abertura da seção desenvolvimento, em que a ouvinte inicia seu relato, o locutor realiza uma repetição - "não aconselha" (linha 7) - que toma parte da elocução da ouvinte "eu não aconselho ninguém / a tomar remédio pra emagrecer sabe?" (linhas 5 e 6), concretizando a função da repetição não só de demonstrar participação mas também de proporcionar expansão, funcionando como uma fábrica de conversação (TANNEN, 1987). Ou seja, com a repetição de parte do 
enunciado da ouvinte, o locutor demonstra seu envolvimento, sua participação - um aspecto crucial da interação - e promove o desenvolvimento do tópico da conversa. Essa repetição acaba por funcionar também como um recurso de manutenção da neutralidade estratégica do locutor, visto que, ao repetir parte do enunciado da ouvinte, o locutor promove o desenvolvimento da conversa sem ter de adotar um posicionamento explícito a respeito do tópico.

$\mathrm{Na}$ sequência, percebemos a ocorrência de outra repetição que, entretanto, é realizada pela ouvinte. Nas linhas 15 e 19 - "porque o remédio atrapalhou a minha cabeça / o remédio atrapalhou a minha cabeça" - a repetição acaba por realçar a criação da imagem e a manifestação de detalhes (também estratégias de envolvimento) no discurso da ouvinte, contribuindo para o ponto do seu relato pessoal. Em seguida, na elocução "ficou DOIda?" (linha 26), é o locutor quem, mais uma vez, utiliza-se do recurso da repetição que, neste caso, assume a função de ratificação do outro, que é assinalada por uma ênfase no item lexical "DOIda". Tal função de ratificação do outro também se concretiza no discurso da ouvinte, como em "TÁ abaixando" (linha 54), em que ela repete parte da elocução do locutor, demonstrando sua concordância e revelando, assim, a realização da estratégia de polidez positiva 'procurar acordo', enfatizando uma concordância emocional. O mesmo acontece na linha 62 "não aconselho ninguém" em que ela repete parte do enunciado do locutor “quer dizer que você não aconselha ninguém?”. Interessante observar que essa elocução do locutor (linha 61), além de ser uma repetição que constrói envolvimento, é uma formulação com a qual o locutor não somente propõe uma direção para a fala subsequente da ouvinte, cooperando para o desenvolvimento do tópico e mantendo um posicionamento neutro, ${ }^{6}$ mas também dá pistas para o fechamento, funcionando como uma forma de concretização da estratégia 'evitar desacordo'.

Além disso, devemos notar que o comportamento discursivo do locutor do programa "Rádio Vivo" é marcado pela demonstração do que Tannen (1989) chama de estilo de envolvimento de 'alta consideração', que demonstra preocupação com as necessidades da face negativa da ouvinte, na medida em que são constantes os backchannels, ou seja, as pistas de retorno de canal, como:

\footnotetext{
${ }^{6}$ Segundo Heritage (1985), a formulação consiste em resumir, sintetizar, interpretar ou desenvolver a essência do que foi dito. Através desse recurso, o locutor não só evita adotar um posicionamento explícito, como também mantém a audiência como o primeiro destinatário da história do entrevistado.
} 
"hum"(linhas 9, 18, 31, 42, 48 e 51) e "sei" (linha 12). Segundo Bazzanela (1990), tais backchannels devem ser considerados marcadores interacionais, pois o seu uso, nas trocas conversacionais, implica um realce das relações sociais entre os interlocutores. Nesse caso, ao usar "hum" e "sei", o locutor está demonstrando atenção, compreensão e mantendo o canal aberto, ao mesmo tempo em que está indicando concordância e assegurando empatia.

Nesse exemplo, a ratificação do enquadre pessoal na interação é muito marcante, sobretudo, em função da empatia que a ouvinte tenta criar com o locutor e da solidariedade que o locutor busca demonstrar em relação à ouvinte. Logo no início, podemos notar que, ao começar a narrar sua experiência, sua história com remédios para emagrecer, utilizando-se do recurso do relato pessoal, a ouvinte expõe, com a elocução "não porque quando eu tinha CEM quilos" (linha 8), a sua própria face, ameaçando-a. Durante toda a interação, esse processo de ameaça da própria face se repete, na manifestação dos detalhes e na criação da imagem, construindo, todavia, envolvimento, como na linha 15 "porque o remédio atrapalhou a minha cabeça", na linha 21 "e passei pra cento e cinquenta quilos" e na linha 25 "NA::da foi eu fiquei DOIda". Dessa forma, ao mesmo tempo em que ameaça a sua própria face, a ouvinte também constrói envolvimento por meio do recurso da narrativa. Sendo assim, todos os esforços do locutor na simulação de um ambiente interacional de intimidade - que favorece o relato de uma experiência de natureza essencialmente ameaçadora à face da ouvinte -, são em torno de práticas protetoras, demonstrando reconhecimento de que o coparticipante (a ouvinte) tem um direito moral a essa proteção (cf. GOFFMAN, 1980). Tal comportamento interacional do locutor fica evidente, sobretudo, nas falas:

(a) "o que que aconteceu com a sua cabeça? você começou a ficar esqueci::da?" (linha 22), em que suas escolhas lexicais por "começou a ficar" (em vez de ficou) e "esquecida" (em lugar de maluca ou doida, por exemplo), demonstram seu desejo de realizar uma mitigação da ameaça à face da ouvinte que ela mesma realizara em seu discurso por meio de sua narrativa;

(b) “é MESmo?” (linha 29) - em que há uma demonstração enfática de envolvimento, conexão emocional, e de consideração (marcada pela ênfase dada à primeira sílaba do item "MESmo"), revelando o uso da estratégia de polidez positiva 'dar solidariedade', preenchendo, segundo Brown e Levinson (1987), o desejo da ouvinte de ser ouvida, compreendida e admirada; 
(c) "É tá baixando né?" (linha 53) e "Oh Conceição ficar com a cabeça ruim deve ser um SOfrimento né?” (linha 65), que demonstram, respectivamente, a realização das estratégias de polidez positiva 'ser otimista' - pela qual o locutor indica reflexividade, ratificando a alegria da ouvinte em perder peso também como sua e demonstrando ter por ela consideração, admiração e, mais uma vez, 'manifestar solidariedade, compreensão e cooperação', que também se manifesta em "é que horror" (linha 68).

Por fim, na sinalização do enquadre de intimidade, observamos, na participação da ouvinte, a ocorrência da estratégia de polidez positiva que busca pressupor, garantir base comum, com a utilização de forma de tratamento familiar, como "meu filho", em "ah meu filho eu fiquei doidinha" (linha 67).

\section{O Programa "Capital na boca do Povo" (Rádio Capital AM)}

Os participantes do programa "Capital na boca do povo", ao estabelecerem uma relação de proximidade, ou seja, o enquadre pessoal, estão coconstruindo suas identidades, basicamente, a partir de: (i) construção de faces (GOFFMAN, 1980) de político de confiança das classes populares para o locutor (que, nessa ocasião, apresentava-se como um candidato em potencial para o cargo de vereador da cidade de Belo Horizonte) e de eleitor em potencial, aquele que vive as injustiças sociais e que se vê como defendido pelo discurso do locutor para o ouvinte e, consequentemente, (ii) demonstração de afiliação social. Vejamos a interação abaixo, que durou 4 minutos e 49 segundos.

(3)

Valdir: locutor

Verônica:: ouvinte

1. Verônica: alô seu Valdir

2. aqui éa Verônica: aqui da bairro São Benedito

$3 . \quad$ [de são Cosme ]

4. Valdir: [o quê que você] deseja Verônica:?

5. Verônica: aqui oh eu queria denunciar

6. É o seguinte

7. aqui tá acontecendo tanta (coisa) da polícia

$8 . \quad$ aí [você] 
9. Valdir: [fala ]Alto (aumento do volume de voz)

10. Verônica: você precisa da polícia miliTAR

11. Valdir: âh?

12. Verônica: você liga pro cento e noventa

13.

eles não atendem a gente

14.

15.

ah: roubou aqui no bairro São Cosme

16. Valdir:

eu não queria me identificar não

17. Verônica:

sei

18.

é:: a gente ligou pra lá

19.

entendeu?

20.

eles fizeram o seguinte

21.

eles falaram que não tinha carro pra mandar

22.

entendeu?

23.

Eles roubaram aqui

24.

Eles oh aqui tá acontecendo a maior pouca vergonha

25. você chama a polícia eles não querem atender você

26. polícia tá tudo (filiado) com ladrão

27. você chama polícia

28. só quando tem droga ou tá acontecendo qualquer coisa assim

29. que eles vêm /.../

30.

31. mas quando é preciso

32. Valdir:

por causa de um assaltante que roubou a casa da gente eles não atendem a gente

33. Verônica: de [pois::::]

34.

[eles fa]lam que não podem atender no momento

35. depois de duas três cinco horas

36. eles vêm na casa da gente de madrugada

37. pra perturbar a gente

38. Verônica:

pra gente fazer ocorrência /.../

39. eles não tão fazendo nada seu Valdir

40. a gente liga pra eles

41. eles atendem a gente com má vontade

42. [quando (incompreensível) ] /.../

43.

44. Valdir: agora a gente fica dentro de casa com medo da gente ser abordada [aí ]

45. [olha] mas oh Verônica: faz o seguinte dá o seu telefone fora do ar 
46. Verônica: hum?

47. Valdir: que eu vou ligar pra você tá bom?

48. Verônica: tá ok

49. Valdir: pode deixar que aqui é sigiloso

50. FAÇAM DENÚNCIA BEM MESMO (gritando)

51. FAÇAM IGUAL A ESSA MOÇA

52. DENUNCIEM ESSES SAFADOS MESMO

53. ESSES ESTUPRADORES SEM VERGONHA

54. QUE NEM OS PRESOS gostam DEle

55. nem-os-pre-sos-gos-tam-DE-le /.../

Em primeiro lugar, vimos que o locutor abre espaço para a ouvinte se expressar pelo enunciado "o quê que você deseja Verônica?”(linha 4), assinalando seu papel institucional, ao mesmo tempo em que promove a construção do enquadre pessoal ao se dirigir à ouvinte usando o seu nome sem os títulos senhora e / ou dona e ao concretizar a estratégia 'dar solidariedade' por meio dessa elocução, o que comprova que um mesmo enunciado pode ser, por um lado, institucional e, por outro, pessoal. Em seguida, a ouvinte também demonstra reconhecimento de uma atividade prevista para seu papel institucional nesse programa, ao iniciar a interação com a elocução "aqui oh eu queria denunciar/É o seguinte/aqui tá acontecendo tanta (coisa) da polícia” (linha 5 a 7), realizando, assim, uma denúncia. A partir desse momento, podemos notar a concretização de uma estratégia de envolvimento para a construção do enquadre pessoal no comportamento discursivo da ouvinte. Estamos nos referindo ao relato pessoal, especialmente, no trecho entre as linhas 10 e 43 "você precisa da polícia miliTAR/você liga pro cento e noventa/ eles não atendem a gente /.../ agora a gente fica dentro de casa com medo/da gente ser abordada [aí ]". Além disso, esse relato é enriquecido por detalhes e imagens - que, segundo Tannen (1989), refletem e criam envolvimento entre os interlocutores na interação, já que os sentimentos associados com tal cena são, em função dessa imagem, disparados, como em: "Eles oh aqui tá acontecendo a maior pouca vergonha /.../ eles não querem atender você /.../ quando é preciso/por causa de um assaltante que roubou a casa da gente /.../ [eles fa]lam que não podem atender no momento/depois /.../ eles vêm na casa da gente de madrugada/pra gente fazer ocorrência /.../eles não tão fazendo nada seu Valdir /.../ eles atendem a gente com má vontade" (linha 23 a 40). A descrição desses detalhes, portanto, colabora para a construção de uma imagem 
que une os interlocutores ao evento descrito, criando, assim, envolvimento e contribuindo para a metamensagem (nos termos de BATESON, 1972). Em outros termos, o relato ou a descrição do self nesse programa, ao mesmo tempo em que constrói envolvimento ao criar cenas que despertam emoções, como a de estar desamparada, desprotegida - "agora a gente fica dentro de casa com medo/da gente ser abordada [aí]" -, serve como uma justificativa não só para a realização de uma denúncia mas também e, principalmente, para a concretização indireta de um pedido por ajuda, pelo socorro com o qual a ouvinte demonstra não poder contar em sua vida social. Assim, a estratégia da indiretividade também surge nos dados desse programa como um recurso de construção de relações de proximidade, uma vez que, ao fazer a denúncia, por meio do relato do self, a ouvinte está, implicitamente, também fazendo um pedido por ajuda na construção do enquadre pessoal, buscando, assim, a coparticipação do locutor na construção do significado.

O locutor, por sua vez, ratifica a construção dessa relação de proximidade, demonstrando reconhecer o enquadre duplo que a ouvinte dera ao seu relato - uma denúncia e um pedido por ajuda - ou, em outras palavras, coconstruindo o significado do relato da ouvinte como denúncia e pedido por ajuda -, ao comprometer-se a dar a ela um atendimento pessoal e particular em: "[olha] mas oh Verônica:/faz o seguinte dá o seu telefone fora do ar/que eu vou ligar pra você tá bom?/pode deixar que aqui é sigiloso” (linha 44 a 49) e, assim, concretizando também a estratégia 'procurar acordo'.

Finalmente, o comportamento discursivo do locutor também se utiliza de padrões sonoros como estratégias de envolvimento. $\mathrm{O}$ uso da rima no "Capital na boca do povo" vem sempre acompanhado pela repetição como forma de dar ritmo à interação e pelas marcações prosódicas de volume alto de voz, como em: "FAÇAM DENÚNCIA BEM MESMO (gritando)/ FAÇAM IGUAL A ESSA MOÇA/DENUNCIEM ESSES SAFADOS MESMO/ESSES ESTUPRADORES SEM VERGONHA/QUE NEM OS PRESOS gostam dele/nem-os-pre-sos-gos-tam-de-le (linha 50 a 55). Durante toda sua fala, há uma cadência sonora que dá ritmo à conversa, que se marca por repetições de algumas partes da elocução, como podemos notar em: "FAÇAM /.../ MESMO /.../ FAÇAM /.../ ESSA /.../ ESSES /.../ MESMO /.../ ESSES /.../ QUE NEM OS PRESOS gostam DEle/nem-os-pre-sos-gostam-DE-le", recebendo a cadência dessa última elocução uma ênfase dada pela sucessão rítmica sílaba a sílaba.

Essa alta densidade de sílabas acentuadas, aumentos e alternâncias do tom e do volume da voz que resultam em picos de volume, variando do 
normal ao mais elevado e estridente, que não só concretizam a estratégia 'exagerar interesse, aprovação', construindo envolvimento mas também colaboram para a projeção da identidade social de político de confiança das classes populares. Com essas pistas prosódicas, o locutor marca, assim, sua cumplicidade com aqueles que ele defende, alinhando-se como "a voz do povo", ratificando, assim, a própria identidade do programa que se define como "Capital na boca do povo". Na voz do próprio locutor "aqui é lugar de atendimento popular/a reclamação popular/a denúncia popular/então nós estamos aqui para ajudar o povo/no contexto de melhoria da sua vida/das reclamações das maldades das injustiças” (ex. 119, p. 166 do corpus). Segundo Bell (1984), "os melhores comunicadores fazem da voz das pessoas a sua própria e da sua, a voz das pessoas".

Assim, locutores e ouvintes coconstroem suas identidades, demonstrando afiliação à classe menos favorecida e desafiliação ou distanciamento da classe privilegiada da estrutura social. Dito de outra forma, no programa "Capital na boca do povo", os interactantes coconstroem - ao estabelecerem relaçóes de proximidade - as suas identidades e a identidade dos ouvintes do programa, sobretudo, demonstrando uma afiliação social que revela parceiros e opositores. Como observam Oliveira e Bastos (2001, p.173):

Esse movimento de identificar antagonistas e opositores é constitutivo do processo de construção de identidade no que se refere a categorias sociais mais amplas, estabelecidas a partir de categorizações binárias, em função de diferenças em relação a outros grupos sociais.

Nessa interação fica claro, no entanto, que, para a projeção dessas identidades, o locutor do "Capital na boca do povo" (diferentemente do locutor do Rádio Vivo) parece estar construindo a si mesmo e ao outro, demonstrando estar trazendo à tona, no discurso, uma certa rudeza e agressividade, principalmente, em suas marcações prosódicas.

Todavia, os participantes não definem, para esse programa, um ethos de impolidez e hostilidade; na verdade, o comportamento discursivo de ambos os interlocutores revela que determinados parâmetros que seriam evidenciadores de poder - como: recusa de cessão de turno, interrupção, assim como ênfase, entonação ascendente, volume de voz de um grito e imperativos - não marcam poder nas interações nesse programa, já que locutor e ouvinte não co-constroem o significado desses recursos como ameaças à face. Em outros termos, toda a expressão dessa rudeza, no "Capital na boca do povo", parece estar à serviço não 
da manutenção da estrutura hierárquica de poder, mas, pelo contrário, da sua dissimulação. Embora o locutor adote um comportamento interacional indicador de poder, ele está usando tais estratégias para estabelecer proximidade com o ouvinte, construindo e reconstruindo, a todo tempo, sua identidade como político de confiança do povo, o que demonstra, como aponta Tannen (1994), a relatividade das estratégias linguísticas, já que aquelas que parecem dominar podem, em um determinado contexto ou na boca de um determinado falante, serem usadas para criar conexão (e vice-versa). Nesse sentido, entendemos que o locutor desse programa, ao usar um estilo de fala enfático, está evidenciando envolvimento, e não poder na interação com o ouvinte.

Assim, um ethos que, aparentemente, contrói-se como hostil e rude é caracterizado por demonstraçōes de uma cultura de polidez positiva baseada em compreensão, aprovação e ratificação que se concretizam, em especial, a partir das estratégias 'exagerar interesse, aprovaçâa' e 'intensificar o interesse do ouvinte', pelas quais os interlocutores demonstram que compreendem, aprovam e apoiam a identidade que cada um projeta para si, para o outro e para a audiência, manifestando uma afiliação social que confirma seus parceiros (a classe menos favorecida) e seus opositores (a classe privilegiada da estrutura social).

Além disso, se nos detivermos na vinheta de identificação do programa, poderemos notar sua forte adequação e coerência em relação ao ethos que os interactantes definem para as interações no "Capital na boca do povo". Por meio da sequência cantada - "Não me (olha) não/eu gosto mesmo é:: da Capital::::Capital::::::" -, que vem seguida por uma fala contundente que anuncia não só a Rádio, o programa, o locutor e o ouvinte como a voz do povo (em discurso direto) mas também os conteúdos a serem veiculados:

$\mathrm{Na}$ Capital, o povo FAla 'o meu barracão caiu eu não tenho nem onde morar', o povo PEde 'eu queria pedir uma cadeira de roda pro meu tio que tá mu::ito necessitado', o povo reCLAma 'eu não tô nem podendo chegar na minha casa, a minha rua tá cheia de buraco, não tem NEM iluminação'. Capital na BOca do povo com "Valdir Barbosa: o repórter do Povo.

Dessa forma, fica estabelecida a atmosfera interacional desse programa, sua audiência-alvo, assim como seu objetivo: atender aos chamados do povo, a quem o locutor se alia ao buscar sua aprovação e ratificação, opondo-se à classe mais favorecida. O fundo musical também colabora para um tom de suspense, semelhante ao de filmes de ação, e funciona como um recurso de realce do tom de denúncia do programa que dá ao povo voz e vez. 


\section{Conclusões}

A análise revelou que, em cada programa, o relato pessoal constrói-se concomitantemente ao enquadre institucional, ou seja, ao coconstruírem relações de proximidade por meio do relato do self, os participantes são também coautores de identidades sociais que se revelam e se constroem no discurso, evidenciando os papéis interacionais preestabelecidos para cada um dos programas.

Assim, na estrutura de participação do programa "Rádio Vivo", o relato pessoal surge em função da atividade prevista para o papel de ouvinte: participar do debate do dia, construindo identidades sociais relacionadas a cada tópico em discussão e, no "Capital na boca do povo", essa estratégia está relacionada à atividade fazer pedidos por ajuda, funcionando como uma justificativa e constrói a identidade de "político de confiança das classes populares" para o locutor e de "eleitor em potencial", "aquele que vive as injustiças sociais" para o ouvinte.

De tudo que expomos a respeito dos dois programas de rádio em análise, foi possível perceber que cada um deles define um ethos específico, baseado não somente nas normas de interação mas também nos valores que subjazem o comportamento discursivo dos participantes. Essa definição da qualidade de interação peculiar a cada programa confirma o rádio como um importante cenário de diálogo da sociedade que, embora se estabeleça em bases institucionais, assume um tom interacional, essencialmente pessoal, marcado por demonstrações de simetria e proximidade.

Este trabalho constata, portanto, que o uso da língua nas situações de interação ouvinte-locutor de rádio demonstra uma redefinição da natureza da interação, marcando uma mudança de uma relação supostamente de distância (institucional) para uma relação de proximidade (pessoal) entre os interactantes, o que comprova, como considera Bell (1984), que nos meios de comunicação de massa, especialmente no rádio, a língua cria uma relação entre o comunicador e sua audiência e não simplesmente responde a uma relação existente, sendo usada ainda como expressão de uma identidade compartilhada com a audiência.

Este trabalho evidencia, portanto, a compreensão do ethos de interações radiofônicas brasileiras que se definem, na sua essência, como lugar de "interação" social pautado, nos dizeres de Da Matta (1979), pelo "horror às distâncias" e pelo desejo à proximidade. 


\section{Referências Bibliográficas}

BASTOS, L.C. Histórias de mulheres e de homens. narrativa, sexo e construção de identidade. The ESPecialist, v. 20, n. 1, p. 17-29, 1999.

BATESON, G. Steps to an Ecology of the Mind. New York: Ballantine Books, 1972.

BAZZANELLA, C. Phatic connectives as interactional cues in contemporary spoken italian. Journal of Pragmatics, v. 14, n. 4, p. 629-647, 1990.

BELL, A. Language style as audience design. Language in Society, v. 13, n. 2, p. 145-204, 1984.

BROWN, P.; LEVINSON, S. Politeness. Some Universals in Language Usage. Cambrige: Cambrige University Press, 1987.

DA MATTA, R. Carnavais, malandros e heróis. Rio de Janeiro: Zahar, 1979.

GOFFMAN, E. Manicômios, prisões e conventos. São Paulo: Perspectiva, 1992 [1961].

GOFFMAN, E. A elaboração da face. Uma análise dos elementos rituais da interação social. In: FIGUEIRA, S. (Org.). Psicanálise e Ciências Sociais. Trad. J. Russo. Rio: Francisco Alves, 1980. p. 76-114.

GOFFMAN, E. Footing. In: RIBEIRO, B. T.; GARCEZ, P. M. (Org.). Sociolinguistica Interacional. Porto alegre: AGE Editora, 1998[1981], p. 70-97. GOFFMAN, E. A representação do eu na vida cotidiana. Petrópolis: Vozes, 1995.

GREATBATCH, D. A turn-taking system for British news interviews. Language in Society, v. 17, n. 3, p. 401-430, 1988.

GUMPERZ, J. Discourse strategies. Cambridge: Cambridge University Press, 1982.

HERITAGE, J. Analysing news interviews: aspects of the production of talk for an overhearing audience. In: T. A., Van Dijk (Ed.). Handbook of Discourse Analysis. London: Academic Press, 1984. v. 3, p. 117-195.

LABOV, W.; WALETZKY, J. Narrative Analysis: oral versions of personal experience. In J. HELM (Org.). Essays on the verbal and visual arts. Seattle: University of Washington Press, 1967.

LABOV, W. The transformation of experience in narrative syntax. In: LABOV, W. Language in the inner city. Philadelphia: University of Philadelphia Press, 1972.

LINDE, C. Life stories, the creation of coherence. New York: Oxford University Press, 1993. 
MARCUSCHI, L.A. Análise da conversação. São Paulo: Ática. Série Princípios, 1991.

OLIVEIRA, M. C. L.; BASTOS, L.C. Saúde, doença e burocracia: pessoas e dramas no atendimento de um seguro saúde. In: RIBEIRO, B. T.; LIMA, C. C.; DANTAS, M. T. L. (Org.). Narrativa, identidade e clínica. Rio de Janeiro: Ediçôes IPUB-CUCA, 2001. p.161-186.

PEREIRA, Maria das Graças Dias. Estratégias de interação no discurso acadêmico falado. 1993. 339f. Tese (Doutorado em Letras: Linguística) - Departamento de Letras, Pontifícia Universidade Católica, Rio de Janeiro, 1993.

RIBEIRO, B. M. T. Papéis e alinhamentos no discurso psicótico. Cadernos de Estudos Lingüisticos. 20, p. 113-38, 1991.

SACKS, H.; SCHEGLOFF, E.; JEFFERSON, G. A Simplest Systematics for the Organization of Turn-Taking for Conversation. Language, v. 50, p. 696-735, 1974.

SCHIFFRIN, D. Narrative as self-portrait: Sociolinguistic constructions of identity. Language in Society, v. 25, n. 2, p. 167-203, 1996.

TANNEN D. Relative focus on involvement in oral and written discourse. In: OLSON, D; TORRANCE, N.; HILDYARD, A. (Ed.). Literacy, Language and Learning. The Nature and Consequences of reading and writing. London: Cambridge University Press, 1984.

TANNEN D. Repetition in conversation. Towards a Poetics of Talk. Language, v. 63, n. 3, p. 574-605, 1987.

TANNEN D. Talking voices. Repetition, dialogue and imagery in conversacional discourse. Cambridge: Cambridge University Press, 1989.

TANNEN D. The relativity of Linguistic Strategies. In: Gender and Discourse. New York: Oxford University Press, 1994. 


\section{ANEXO}

Foram utilizadas as seguintes convenções de transcrição:

Pausa de menos de meio segundo: ..; Pausa de meio segundo: ...; Pausa de um segundo: ....; Pausa superior a um segundo: $(1,5)$ números entre parênteses; Descida leve, sinalizando final de enunciado: . ; Descida leve, sinalizando que mais fala virá: , ; Subida rápida, sinalizando interrogação: ?; Fragmentação da unidade entonacional: - -

Truncamento: -; Alongamento: : :: ::::; Ênfase: MAIÚSCULA; Silabação letra-a-letra: - - -; Repetição: reduplicação de letra ou sílaba; Observações sobre ritmo e volume de fala: ( ); Pausa preenchida: eh, oh, ah, hum hum, âhã; Indicação de transcrição parcial: /.../; Iniciação simultânea do turno: [[; Continuação da fala: =; Sobreposição de vozes: [ ] ]. (Critérios adaptados de: MARCUSCHI (1991), RIBEIRO (1991) e TANNEN (1989)).

Recebido em janeiro de 2010. Aprovado em março de 2010. 